\title{
Study on Individual Distance of the Non-Japanese for the Small Mobile Robot
}

\author{
Shun Ota and Akiko Watanabe \\ School of Science and Technology for Future Life, Tokyo Denki University, Tokyo 120-8551, Japan
}

\begin{abstract}
This study seeks to establish techniques of architecture planning for living robots and human together. This experiment is elemental step to search relations between a small mobile robot and human. This experiment is "How can a small mobile robot approach to individuals distances of foreigners (non-Japanese) up to the point where foreigners (non-Japanese) do not feel like approaching any more". It focuses on a small mobile robot and identifies distances at which the robot can approach to individuals, particularly adult foreign male. This paper clarifies how the individual distances change by the robot's speed and angle of approach varies.
\end{abstract}

Key words: Small mobile robot, individual distance, living space, foreigners (non-Japanese).

\section{Introduction}

Recently, robotic technology has been introduced into the living space, inside of buildings for making up human work and production. This current is caused aging society with fewer children. A lot of useful tools, machines and robots have being produced for all, but they mainly have been considered for putting safety, convenience, function and intimacy into them [1].

It is necessary to consider problems except function of robot, for example human motivation and power decrease for human under robot's help. It was called "disuse syndrome" and in case of people's living spaces introduce robots, it have not considered psychological influences for human as unified space and robots yet [2].

On the other hand, the income of Japan with aging society and fewer children, and the GDP (gross domestic product) is predicted decrease. From the effects of globalization with the plan to increase revenues from abroad, foreign workers and foreign tourists in Japan are expected to increase. Presuppose global society surrounding, it is necessary for people's future to consider space of living close human and robot together.

Corresponding author: Shun Ota, M.Arch., research field: architecture planning. E-mail: 11fma11.0211@gmail.com.
This study is part of basic research for the technology plan of living space in harmony with the robot. Based on these backgrounds, this elementary stage experiment conducted to explore the relationship between people and small robots. In the experiment, adult males and non-Japanese to stay in Japan for the subject, and the factor was "attitude", "country", "approach angle" and "moving speed" of the robot.

In this study, to clarify the individual distance the robot moves towards adult males of non-Japanese, compared to Japanese adult males. Then, to clarify the robot will give effect to Japanese and non-Japanese, what may cause such a difference in architectural space.

\section{Methods}

In the experiment to measure the individual distance of this time, focusing on the attitude of the two chair-sitting and standing, in the first experiment was the subjects standing, and in the second experiment was chair-sitting.

Also conducting a questionnaire survey on a subject such as height, age and questions about the space where the experiment before the experiment, and questionnaire survey conducted after the experiment on the robot experiments, too. 


\subsection{Setting of Experiment Condition}

Experiment was carried over to December 26, 2011 until March 12, 2012, and 27 male subjects who were non-Japanese to stay in Japan from 21 to 39 years old (Table 1). Average of age is 26 years, and average of height is $177.1 \mathrm{~cm}$. Eyesight of the subjects, more than 0.7 (14/20 vision) in all, there are no people with disabilities to walk or avoid a small mobile robot (abbreviated as "robots" or later: Fig. 1). Experiment done in the gymnasium is considered relatively few physical constraints. The robot approaches the subject from the point of straight $5 \mathrm{~m}$, over this time in the direction of the front of $0^{\circ}, 45^{\circ}, 90^{\circ}, 135^{\circ}, 180^{\circ}$, it measured the distance which the subject do not want to be approached by the robot any more (Figs. 2 and 3 ). Subjects can use the wireless remote control and carry out in a way to stop the small mobile robot. Before the experiment, it conducted a questionnaire survey about the subject and the robot. In the experiment, subjects were taught "please move the face without changing the orientation of the body and watch the robot", then experiment was started after the teachings, and carried out a survey of impressions for the robot after the experiment was finished.

\subsection{Method of Measure}

The measurement was measured with tape measure, up to the front body of the robot from the center of the plantar surface of the subject. About measurement range, there were not seen the difference from right and left in the personal space of subjects [3]. According to this, it measured only the right half considered the efficiency of the experiment (Fig. 3).

\subsection{About Robot of This Experiment}

Robot was used in the experiment, the independent two-wheel-drive systems, dimensions are $120 \mathrm{~mm}(\mathrm{~W})$ $\times 130 \mathrm{~mm}(\mathrm{D}) \times 70 \mathrm{~mm}(\mathrm{H})$. Function of the robot is only to keep the speed of each run, stop and run away. It is possible to $5 \mathrm{~m}$ by the infrared sensor that originate from the remote control (Fig. 2).
Table 1 Non-Japanese to stay in Japan.

\begin{tabular}{|c|c|c|}
\hline Country & Number & \\
\hline China & 12 & \\
\hline South Korea & 3 & \\
\hline Taiwan & 2 & \\
\hline France & 2 & \\
\hline Sweden & 2 & \\
\hline Thailand & 1 & \\
\hline Indonesia & 1 & \\
\hline India & 1 & \\
\hline Nepal & 1 & \\
\hline Greece & 1 & \\
\hline Germany & 1 & \\
\hline Total & 27 & \\
\hline & & $\begin{array}{l}\text { W: } 120 \mathrm{~mm} \\
\text { D: } 130 \mathrm{~mm} \\
\mathrm{H}: 70 \mathrm{~mm} \\
\text { Moving speed: } \\
0.08 \mathrm{~m} / \mathrm{s}, 0.24 \mathrm{~m} / \mathrm{s}\end{array}$ \\
\hline
\end{tabular}

Fig. 1 Using robot of this experiment.

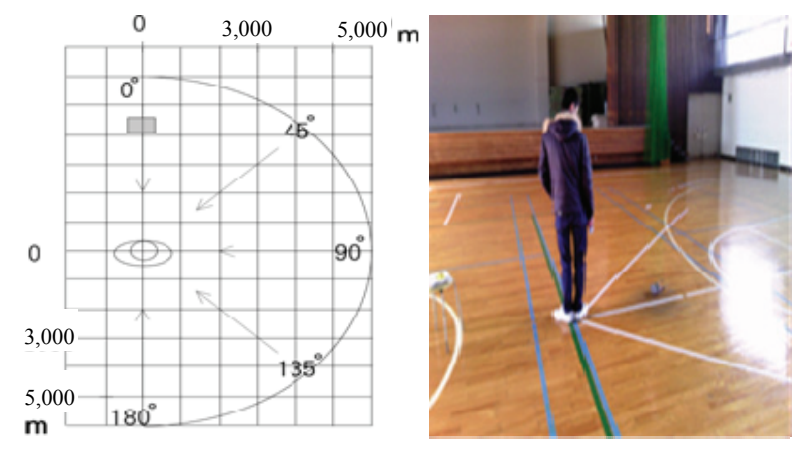

Fig. 2 Look of experiment place.

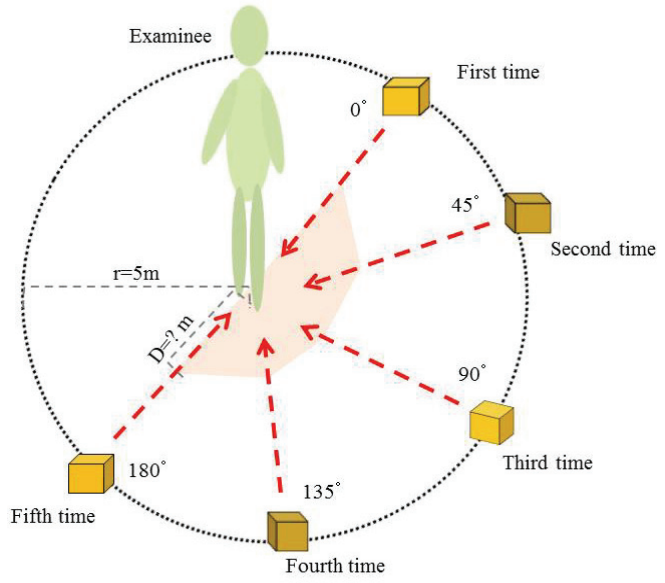

Fig. 3 Image of this experiment. 


\section{Results}

\subsection{In Case of Standing}

Standard deviation was determined to be an indicator of the overall variability so that there are individual differences in the data. Representation of the average value of individual distance for each speed approaching the speed and angle for each of the subjects are shown in Figs. 4 and 5.

About individual distance, compared to $0.24 \mathrm{~m} / \mathrm{s}$ and $0.08 \mathrm{~m} / \mathrm{s}$, at the time of $0.08 \mathrm{~m} / \mathrm{s}$ is close shorter $5.8 \mathrm{~cm}$ than $0.24 \mathrm{~m} / \mathrm{s}$ in case of robot approached to subject in the direction of the front of $0^{\circ}$. Only the cases of the front of $90^{\circ}, 135^{\circ}$ and $180^{\circ}$ were not seen much difference, but this case is influenced by speed than the others directions. According to analysis of between-subjects effect, speed of significance probability is 0.802 , direction is 0.911 , is only slightly (Figs. 4 and 5).

\subsection{In Case of Chair-Sitting}

In the Section of 3.1, standard deviation was determined to be an indicator of the overall variability so that there are individual differences in the data. Representations of the average value of individual distance for each speed approaching the speed and angle for each of the subjects are shown in Figs. 6 and 7.

Compared in the same manner as 3.1, at the time of $0.08 \mathrm{~m} / \mathrm{s}$ is close short $20.5 \mathrm{~cm}$, in case of robot approached to subject in the direction of the front of $0^{\circ}$. And the case of in the direction of the front of $45^{\circ}$ is close short $9.9 \mathrm{~cm}$ at $0.08 \mathrm{~m} / \mathrm{s}$ speed but, in the other direction was not seen much difference (Figs. 6 and 7).

\subsection{Questionnaire Survey}

A questionnaire survey was conducted before and after this experiment. In a survey before the experiment, was carried out in order to grasp the image or impression for conventional robots. In a survey after the experiment was carried out in order to

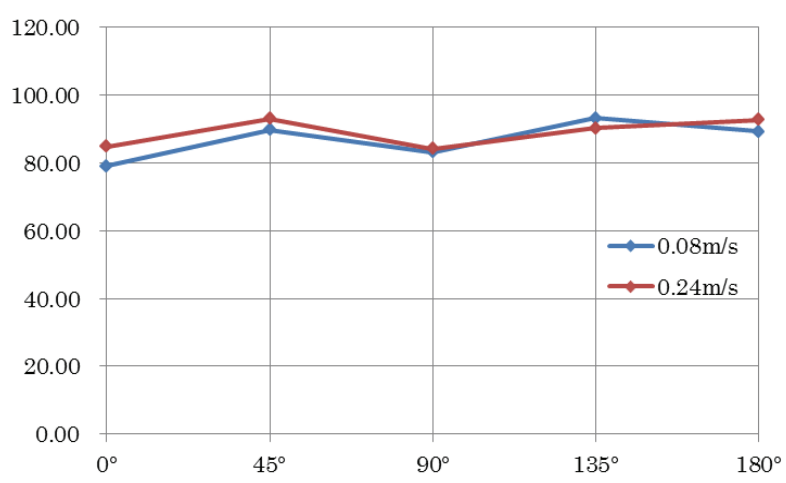

Fig. 4 Average in case of standing.

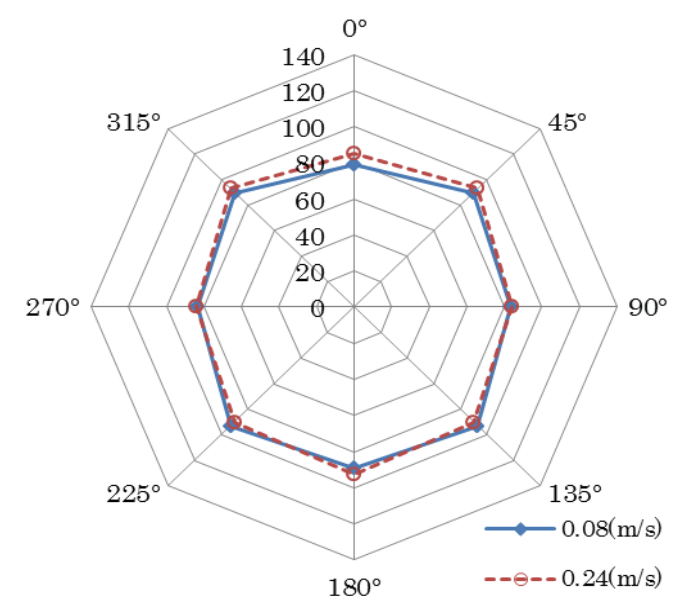

Fig. 5 Individual distance field in case of standing.

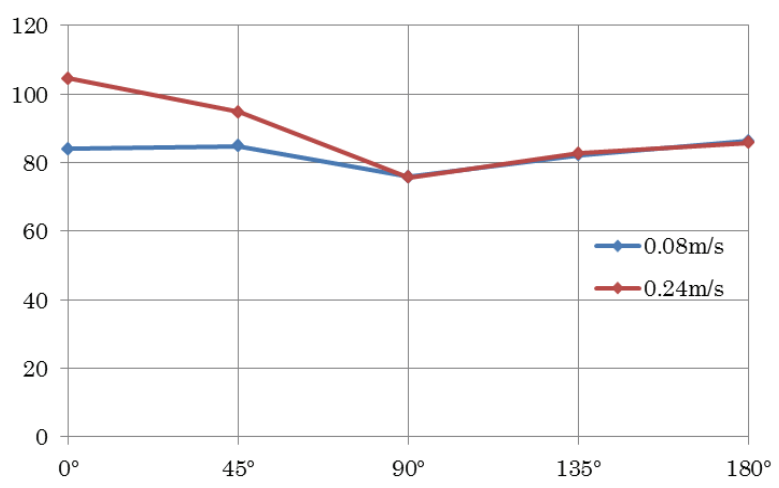

Fig. 6 Average in case of chair-sitting.

clarify about which kind of robot do you want in the future and impression of the robot used in this experiment.

First of all, in questionnaire before the experiment, "How do you feel the size of the space of the gymnasium in the experiment?"-nine persons 
answered "very large", 15 persons "large", three persons "normal". This space of the gymnasium might have been less constrained physical environment as a place to experiment. "Do you like robot?"-26 persons answered "Yes", one person "No". "Do you think robot become a family?"-14 persons answered "Yes", 13 persons "No". It seems they have no idea and that it is difficult to imagine and have a feeling in the present life.

Next, in the questionnaire survey after the experiment, "What did you have impression of the robot used in the experiment?"-13 persons answered "Like a toy", 10 persons "Like a pet", eight persons "Like furniture and household", six persons "Like a car bicycle", one person "Like a partner and friend". "What do you want functions of robot?"-21 persons answered "Tell me information of mail, weather, traffic and earthquake", 18 persons "Speaking and get conversation", 14 persons "Turn on or off household and light in home with internet", 14 persons "Become cute with robot's cover", eight persons "Tell a time", seven persons "Bring a drink and check mail", six persons "Baby sit", four persons "Management money", four persons "Others, Shopping, Disposal bomb". Think about this, the look and design attract people and they want functions, for example, to use wireless internet in conjunction with household, weather, traffic and emergency earthquake information.

\section{Consideration}

In the case of standing, but only in the direction of the front of 900 in width, was not seen much difference in the time of $0.24 \mathrm{~m} / \mathrm{s}$ and the time of $0.08 \mathrm{~m} / \mathrm{s}$. So, it deems that examinee's vigilance for the weaken robot without influence of the robot approaching speed, except the direction of the front of $0 \mathrm{o}$ and 450 .

In case of chair-sitting, the direction of the front of $90^{\circ}$ until $180^{\circ}$, were not seen much difference, in the case of $0^{\circ}$ to $45^{\circ}$ can be seen a big difference. This is, it is deemed that the robot approaching distance is

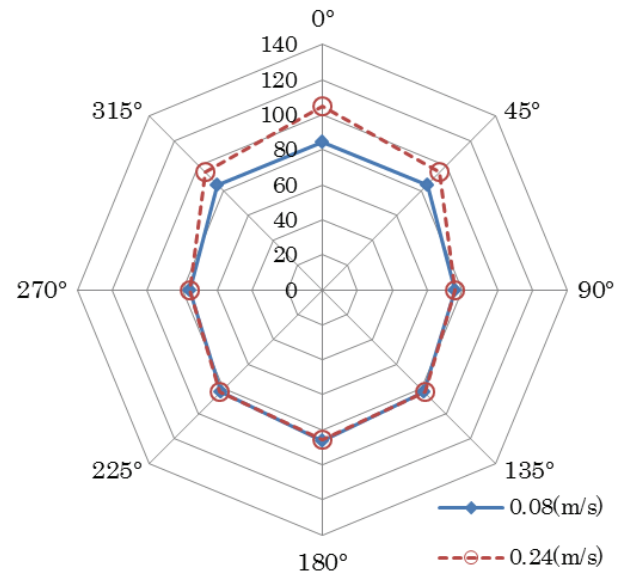

Fig. 7 Individual distance field in case of chair-sitting.

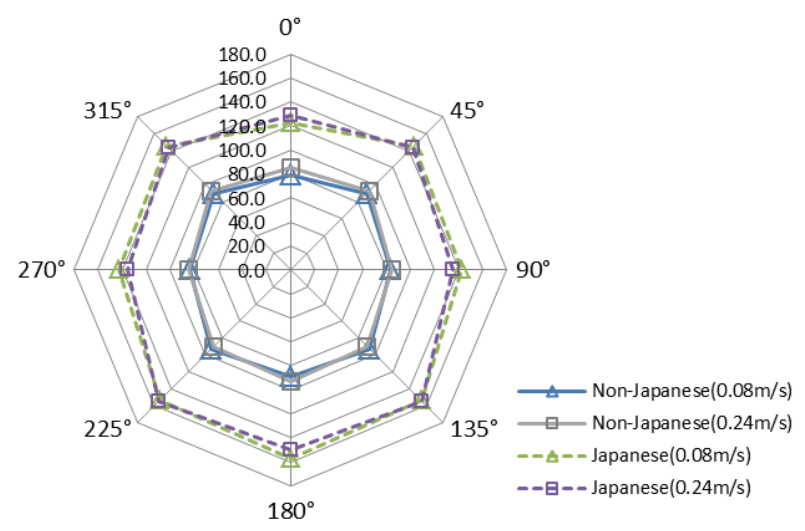

Fig. 8 Compared with average of Japanese in case of standing.

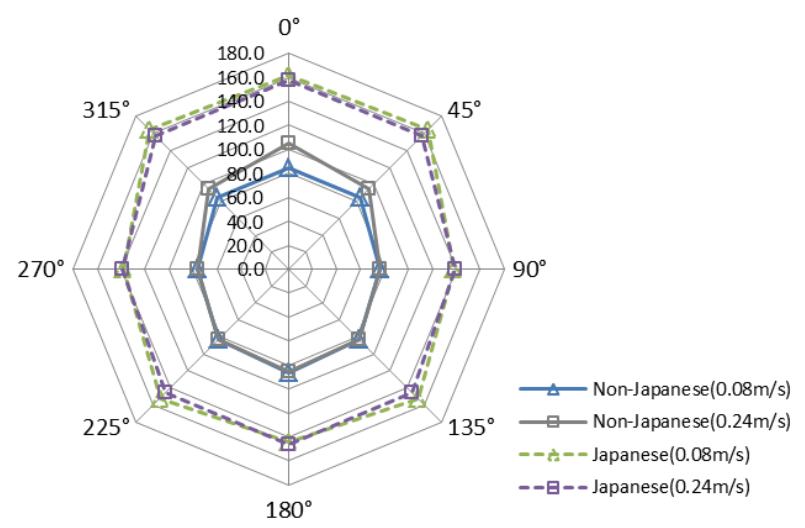

Fig. 9 Compared with average of Japanese in case of chair-sitting.

considered to be affected by enter or not to enter the field of view, not effects of speed.

\section{Conclusions}

From these experiments, the following three results 
were obtained: (1) In case of standing, there are few influences of the robot's approaching speed only direction at angle of $90^{\circ}$ to front; (2) In case of chair-sitting, there are few influences of the robot's approaching speed only directions at angle of $90^{\circ}$, $135^{\circ}$ and $180^{\circ}$ to front. And, there are a few influences of "existence of the robot with examinee's eyesight" and "the robot's approaching speed" only directions from front and at angle of $45^{\circ}$ to front; (3) The robot could approach to foreigners (non-Japanese) than Japanese in cases of standing and chair-sitting. The difference is more than $43 \mathrm{~cm}$ in all directions in case of standing. On the other hand, the difference is more than $53 \mathrm{~cm}$ in all directions in case of chair-sitting too (Figs. 8 and 9).
When the subjects recognize the robot, eyesight of the subjects during the experiment even though there is no much difference between the Japanese also non-Japanese, why there are differences in distance to the robot approaching, the authors think they come from the different of ethnicity and height.

\section{References}

[1] H. Hashimoto, A. Watanabe, Design for the Intelligent Space, NTT Press, Japan, 2004.

[2] Y. Matsumoto, Aging and Workforce in Era of 10 Billion People, Newton Press Japan, Japan, 2012, p. 46.

[3] M. Aoki, A. Watanabe, A study on the distances of an upright/char-sitting small mobile robot to male adult individuals, Journal of Architecture, Planning and Environmental Engineering $76 \quad$ (664) (2011) 1093-1100. 